\title{
Chemical dissection of the cell cycle: probes for cell biology and anti-cancer drug development
}

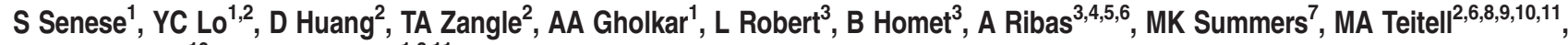 \\ R Damoiseaux ${ }^{10}$ and JZ Torres ${ }^{*, 1,6,11}$
}

Cancer cell proliferation relies on the ability of cancer cells to grow, transition through the cell cycle, and divide. To identify novel chemical probes for dissecting the mechanisms governing cell cycle progression and cell division, and for developing new anticancer therapeutics, we developed and performed a novel cancer cell-based high-throughput chemical screen for cell cycle modulators. This approach identified novel G1, S, G2, and M-phase specific inhibitors with drug-like properties and diverse chemotypes likely targeting a broad array of processes. We further characterized the M-phase inhibitors and highlight the most potent M-phase inhibitor MI-181, which targets tubulin, inhibits tubulin polymerization, activates the spindle assembly checkpoint, arrests cells in mitosis, and triggers a fast apoptotic cell death. Importantly, MI-181 has broad anti-cancer activity, especially against BRAF ${ }^{V 600 E}$ melanomas.

Cell Death and Disease (2014) 5, e1462; doi:10.1038/cddis.2014.420; published online 16 October 2014

The cell cycle is a set of coordinated events that culminate in the formation of two cells from one mother cell. It's composed of four major phases; G1 (growth phase 1), S (DNA synthesis phase), G2 (growth phase 2) and M (mitosis), which function to integrate environment sensing signaling pathways with cell growth and proliferation. ${ }^{1}$ Cancer cells often deregulate the cell cycle and undergo unscheduled cell divisions, therefore inhibition of the cell cycle represents an opportunity for therapeutic intervention in treating proliferative diseases like cancer. ${ }^{2}$ Most anti-cancer drugs perturb the proliferation cycle of tumor cells by inhibiting/damaging cell cycle events, which activate checkpoints, arrest cells and induce apoptosis. ${ }^{3}$ For example, inhibitors targeting DNA replication (5-fluorouracil) and cell division (microtubule-stabilizing paclitaxel) have been used successfully for treating a broad array of cancers including breast and colorectal cancers. ${ }^{2}$ Nevertheless, due to toxicity issues, drugs targeting the cell division machinery like mitotic kinases (AurKA/B and Plk1) and kinesins (Kif11 and CENP-E) have been developed. ${ }^{3}$ However, these drugs have shown limited efficacy in vivo. ${ }^{4}$ Thus, there is a critical need to identify novel drug-like molecules that inhibit cancer cell cycle progression, which can be developed into novel cancer therapies.

Genome wide studies aimed at depleting the expression of human genes and characterizing their contribution to cell cycle progression have generated a wealth of information regarding the enzymatic machinery required for proliferation. ${ }^{5}$ These enzymes have become the focus of targeted screening campaigns aimed at finding inhibitors to their activities. For example, an in vitro chemical screen targeting Plk1 identified the small molecule BI2536. ${ }^{6}$ BI2536 was not only used to define novel roles for Plk1 during cell division, it was further developed into an anti-cancer drug whose efficacy is being evaluated in clinical trials. ${ }^{7}$ Therefore, beyond their therapeutic potential, inhibitors can be used as molecular probes for dissecting the function of enzymes critical for cell cycle progression in an acute and temporal manner. However, there are no inhibitors to the majority of the cell cycle machinery and the discovery and characterization of such inhibitors would aid our ability to understand the mechanisms regulating cell division.

Although molecularly targeted screens have grown in popularity, they rely on the previous identification and validation of specific cancer targets with druggable activities/ interactions. ${ }^{8}$ As an alternative, unbiased high-throughput chemical screens have tried to identify inhibitors to a single cell cycle phase ${ }^{9-15}$ which limited their ability to identify novel antiproliferative agents to other phases of the cell cycle. Nonetheless, G2-phase, M-phase, and cytokinesis screens successfully identified inhibitors to Kif11, Plk1, RhoA, and microtubules. ${ }^{9-15}$ These inhibitors aided the functional characterization of these proteins and were instrumental for

\footnotetext{
${ }^{1}$ Department of Chemistry and Biochemistry, University of California, Los Angeles, CA, USA; ${ }^{2}$ Department of Bioengineering, University of California, Los Angeles, CA, USA; ${ }^{3}$ Department of Medicine (Division of Hematology-Oncology), David Geffen School of Medicine, University of California, Los Angeles, CA, USA; ${ }^{4}$ Department of Molecular and Medical Pharmacology, David Geffen School of Medicine, University of California, Los Angeles, CA, USA; ${ }^{5}$ Department of Surgery (Division of SurgicalOncology), David Geffen School of Medicine, University of California, Los Angeles, CA, USA; ${ }^{6}$ Jonsson Comprehensive Cancer Center, University of California, Los Angeles, CA, USA; ${ }^{7}$ The Department of Cancer Biology, Lerner Research Institute, Cleveland, OH, USA; ${ }^{8}$ Department of Pathology and Laboratory Medicine, David Geffen School of Medicine at the University of California, Los Angeles, CA, USA; ${ }^{9}$ Broad Stem Cell Research Center, University of California, Los Angeles, CA, USA; ${ }^{10}$ California NanoSystems Institute, University of California, Los Angeles, CA, USA and ${ }^{11}$ Molecular Biology Institute, University of California, Los Angeles, CA, USA

*Corresponding author: JZ Torres, Department of Chemistry and Biochemistry, University of California, 607 Charles E Young Drive East, Los Angeles, CA 90095, USA. Tel: +1 310206 2092; Fax: +1 310206 5213; E-mail: torres@ chem.ucla.edu

Abbreviations: $\mathrm{p}-\mathrm{H} 3$, phospho-histone H3; CSNAP, Chemical Similarity Network Analysis Pulldown; SAC, spindle assembly checkpoint; $\mathrm{IC}_{50}$, half maximal inhibitory concentration

Received 17.7.14; revised 27.8.14; accepted 28.8.14; Edited by A Stephanou
} 
developing drugs with therapeutic potential. However, these screens were conducted with a limited number of compounds (100-38000) or cell extract fractions, with several screens using the same library of 16320 compounds, thus limiting compound diversity, chemical coverage, and opportunities for novel discoveries. Most screens also lacked chemical analyses to understand the physiochemical properties of bioactive compounds and their cellular targets. In addition, previous screens have not analyzed the four phases of the cell cycle as a biological system. Thus, there is a critical need to develop new screening strategies to discover novel anticancer drugs.

This, prompted us to establish an integrated highthroughput screening cell-based strategy for identifying small molecule cell cycle modulators, for use in dissecting the mechanisms of cancer cell division, and for developing novel cancer therapies. We report the development of this novel cellbased screening platform, the discovery of cell cycle phase specific inhibitors, the chemical analyses of these inhibitors, the cell culture characterization of cell division inhibitors, and the detailed examination of Ml-181, which has potent anticancer activity, especially against melanomas.

\section{Results}

Discovery of cell cycle modulators. To discover novel cell cycle phase specific inhibitors, human HeLa cancer cells were plated into 384-well plates and a diverse compound library (79827 small molecules) encompassing broad chemical space was used to place one compound per well at $10 \mu \mathrm{M}$ final concentration (Figures $1 \mathrm{a}$ and $\mathrm{b}$ and Supplementary Table 1). These compounds were preselected based on their drug-like properties: predominantly conform to Lipinski's rule of five for acceptable molecular properties for orally active drugs in humans. ${ }^{16}$ Twenty hours later, the cells were fixed and stained with the DNA-selective stain Vybrant DyeCycle Green, which is cell membrane permeant and after binding to DNA emits a fluorescent signal that is proportional to DNA mass when exited at $488 \mathrm{~nm} .^{17}$ Plates were scanned with a fluorescence micro-plate cytometer and a cell cycle histogram profile was generated for each well, which had been treated with one compound (Figure 1b). Cell cycle profiles were grouped and ranked according to the extent of G1, S, and G2/M arrest. The top hits from each phase were cherry picked and retested in triplicate and only those testing positive were considered further. In total we uncovered 69 G1-phase inhibitors (>4 S. D. from the mean), 148 S-phase inhibitors ( $>5$ S.D. from the mean), and 273 G2/M-phase inhibitors (\% G2/M $\geq 67 \%$ ) (Figures 1c and e and Supplementary Table 2). A representative example of each compound class and their associated cell cycle profiles are indicated in Figures $1 \mathrm{f}-\mathrm{h}$.

To distinguish between compounds that arrest cells in G2phase or M-phase, the 273 G2/M compounds were subjected to a secondary high-throughput screen, where cells were fixed and co-stained with the DNA dye Hoechst 33342 and a Alexa488 fluorescently labeled antibody that recognizes phosphohistone $\mathrm{H3}(\mathrm{p}-\mathrm{H} 3)$, which is specifically phosphorylated in mitosis $^{18,19}$ (Figure 1i). This analysis revealed that 266 compounds arrested cells in mitosis and 7 arrested cells in G2-phase (Figure 1j and Supplementary Table 2). In total, the screen resulted in a $0.613 \%$ cell cycle modulator hit rate, with $0.086 \%$ G1-phase inhibitors, $0.185 \%$ S-phase inhibitors, $0.009 \%$ G2-phase inhibitors, and $0.333 \%$ M-phase inhibitors (Figure $1 \mathrm{k}$ ). These results indicated that our cell cycle profile based approach successfully identified inhibitors to all phases of the cell cycle and likely a broad array of targets.

Compound chemical analysis and target prediction. To understand the physiochemical properties of compounds within each cell cycle class, we analyzed the chemical structures of the top compounds from each phase using our newly developed Chemical Similarity Network Analysis Pulldown (CSNAP) computational program. CSNAP searched the ChEMBL database for compounds sharing chemical similarity to hit compounds, retrieved the bioactivity information of each compound found in the ChEMBL database and organized these compounds into network similarity graphs sharing common chemotypes. An implemented scoring function (S-score) was used to score target assignments by counting the target annotation frequency in the nearest neighborhood of query compounds. The predicted compound on/off-targets represented by the S-score were visualized on heatmaps (scaled from 0 to 1 ) and the most prominent targets were selected from the top peaks, which correlated with the cumulative S-score ( $\sum$ S-Score) of each assigned target in the target spectrum. This approach previously allowed us to successfully identify major drug targets for M-phase compounds, which included tubulin targeting compounds as well as novel ligands not previously annotated in bioactivity databases. CSNAP analysis of the 69 G1-inhibitors, 148 S-inhibitors, and 7 G2-inhibitors, resulted in the identification of 64 G1 chemotypes, 68 S chemotypes, and 5 G2 chemotypes, respectively. These results indicated that our screening had discovered phase specific and structurally diverse cell cycle inhibitors (Figures $2 \mathrm{a}-\mathrm{c}$ and Supplementary Table 3).

CSNAP analysis of G1-phase compounds identified kinase inhibitors like Staurosporine, Tyrphostin, and their analogs that mimicked the ATP substrate of PKC and EGFR, which were known to block the MAPK signaling pathway critical for tumor proliferation $^{20-25}$ (Figures 2d and g). In addition, compounds capable of modulating the intracellular calcium concentration including the ion channel inhibitors Thapsigargin (sarcoendoplasmic reticulum $\mathrm{Ca}^{2+}$ ATPase inhibitor), Ouabain $\left(\mathrm{Na}^{+} / \mathrm{K}^{+}\right.$ATPase inhibitor), and the ionophore antibiotic A-23187 were also identified ${ }^{26-28}$ (Figures $2 d$ and g). This was consistent with reports indicating that calcium is an important secondary messenger and that oscillatory calcium signaling is required for MAPK activity and cyclin D1/E synthesis at the G1/S transition. ${ }^{26}$ CSNAP analysis of S-phase compounds indicated that a group of compounds including 5309022 and 5113916 were likely inhibiting ribonucleotide reductase (catalyzes the reduction of ribonucleotides to deoxyribonucleotides; the building blocks for DNA replication and repair $^{29}$ ) activities by iron chelation through a hydrazone motif similar to that of Triapine and its analog $311^{29}$ (Figures $2 e$ and $h$ ). In addition, two GSK3 $\beta$ inhibitors (5100772 and 5583777) were identified among the S-phase 
a

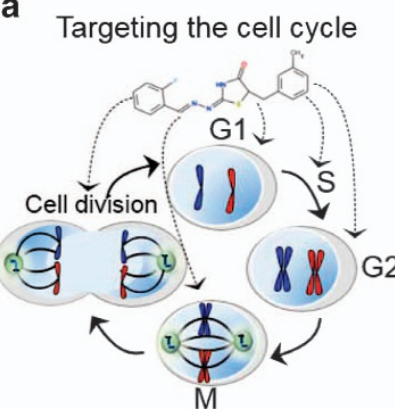

c

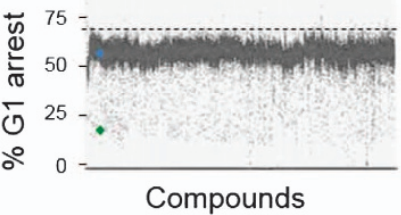

f

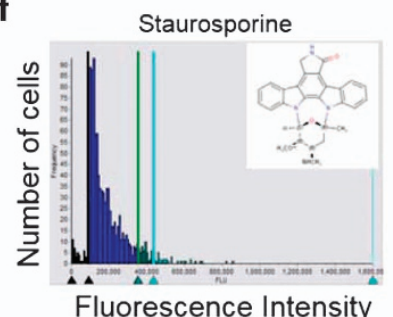

i

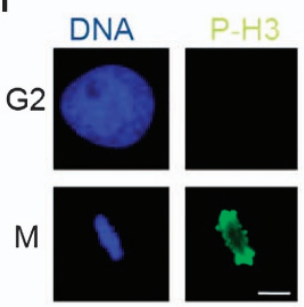

b

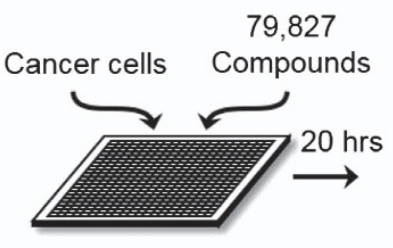

d

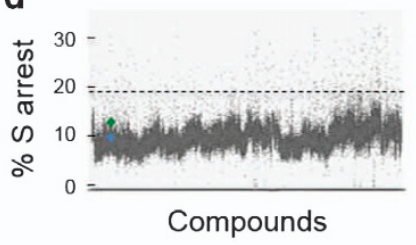

g

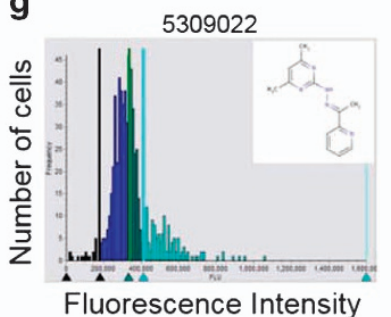

j

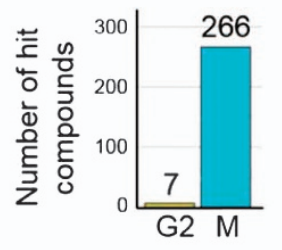

Cell cycle profile/well
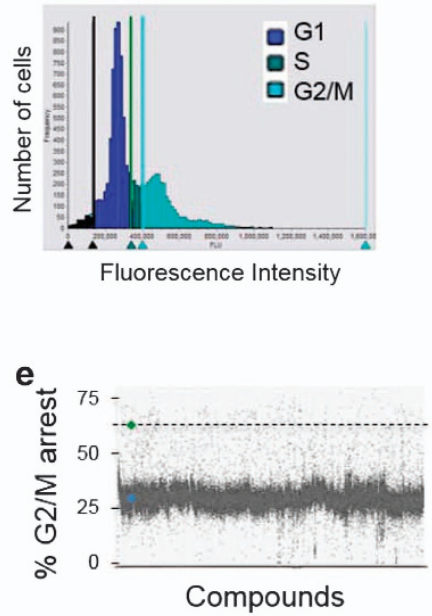

h

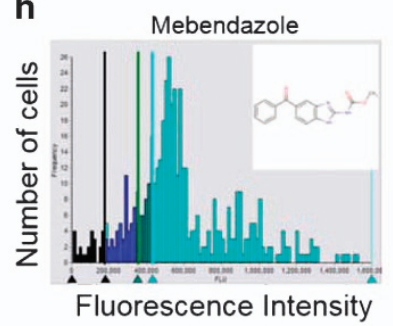

k

Summary of screen hits

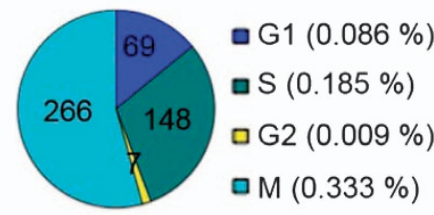

Figure 1 Identification of cell cycle phase specific inhibitors through a novel cell-based high-throughput small molecule screening approach. (a) Targeting the cell cycle in the treatment of cancer. (b) Cell-based high-throughput screening (HTS) of 79827 drug-like molecules for cell cycle modulators. Twenty hours post compound treatment, HeLa cancer cells were fixed and stained with Vybrant DyeCycle green, and a high-content cytometer was used to generate a cell cycle profile for each compound. (c-e) Scatter plots of percent G1, S, and G2/M arrest for all compounds. The cutoffs for G1-phase and S-phase inhibitors were set at $>4$ and $>5$ S.D. from the mean, respectively. The cutoff for G2/M inhibitors was set at $\geq 67 \%$ G2/M arrest. (f-h) Examples of G1, S, and G2/M-phase arresting compounds and their cell cycle profiles. (i) Immunofluorescence HTS assay for distinguishing G2-phase inhibitors from M-phase inhibitors. Cells were co-stained with $1 \mu \mathrm{g} / \mathrm{ml} \mathrm{Hoechst} 33342$ (blue) and Alexa-488-phospho-histone-H3 (p-H3, green). Mitotic cells are positive for $\mathrm{p}-\mathrm{H} 3$. Bar indicates $5 \mu \mathrm{m}$. (j) Summary of screen results indicating that 266 compounds arrest cells in mitosis and 7 compounds arrest cells in G2-phase. (k) Screen summary plot of percent hit rate indicates that M-phase inhibitors were the most abundant. (b-k) See also Supplementary Table 2

inhibitors; consistent with its role in regulating cyclin D1 expression required for S-phase entry and progression ${ }^{30-32}$ (Figures 2e and h). CSNAP analysis of the seven G2-phase compounds identified DNA topoisomerase II (TOP2) inhibitors including Etoposide and Amsacrine-like analogs ${ }^{33}$ (Figures $2 f$ and i). These DNA intercalating agents trap TOP2:DNA covalent complexes, which induce DNA damage and G2 checkpoint arrest. ${ }^{34}$ Thus, CSNAP highlighted compounds with known anti-proliferative properties and analogs of these compounds that may be more efficacious. Most importantly, CSNAP identified many novel compounds not sharing chemotype similarity to compounds in bioactivity databases that represent new anti-proliferative agents. Finally, it provided key information for selecting lead compounds with diverse mechanisms of action and targets that perturb distinct cellular pathways essential for cell cycle progression.

Characterization of M-phase inhibitor potency. Due to the large number and chemical diversity of M-phase inhibitors, the current lack of chemical probes to study cell division and the need for novel antimitotics, we focused on the detailed characterization of mitotic inhibitors. To assess the potential of the $\mathbf{2 6 6}$ mitotic inhibitors as anti-cancer agents, they were re-synthesized and the 211 that passed quality control 
a

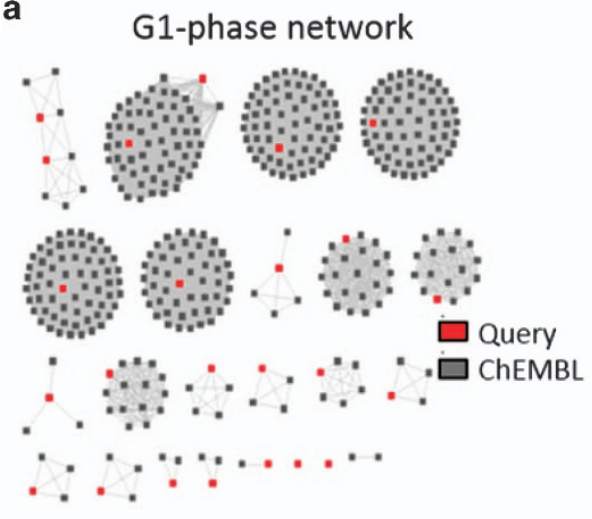

d
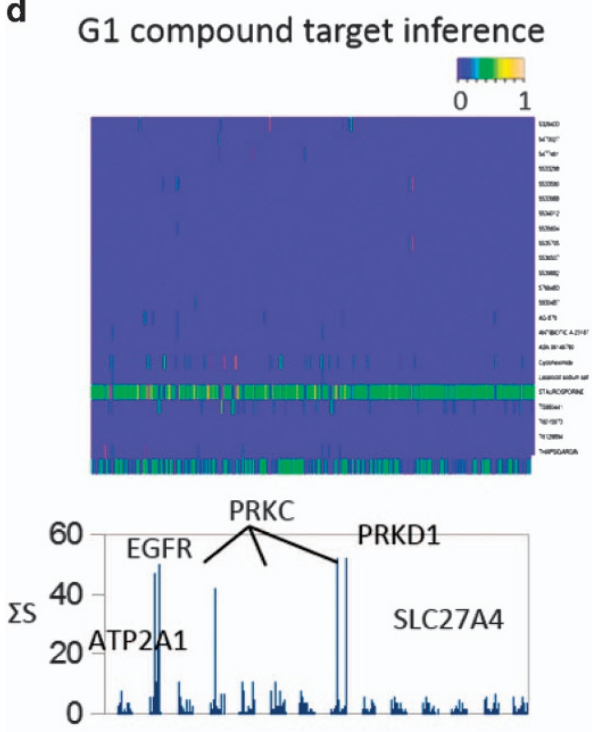

g
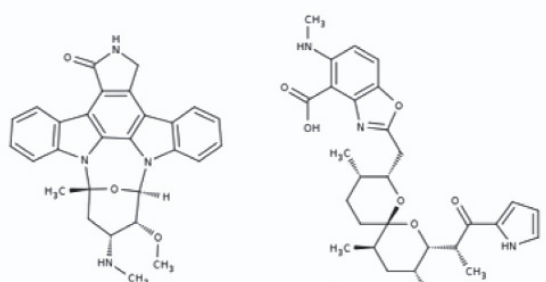

A-23187 ${ }^{\mathrm{CH}_{3}}$

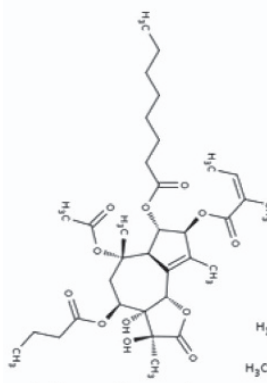

Thapsigargin

\section{b}

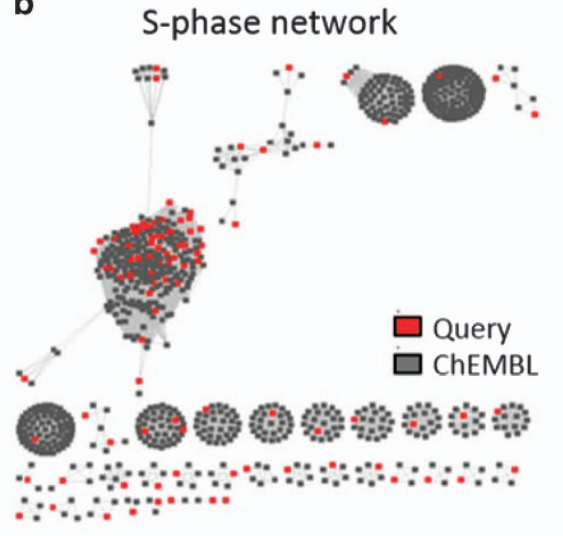

e

$S$ compound target inference
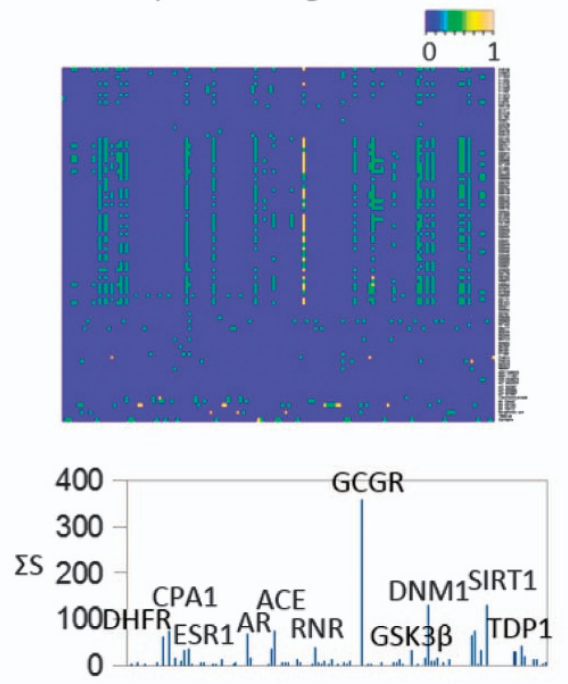

h
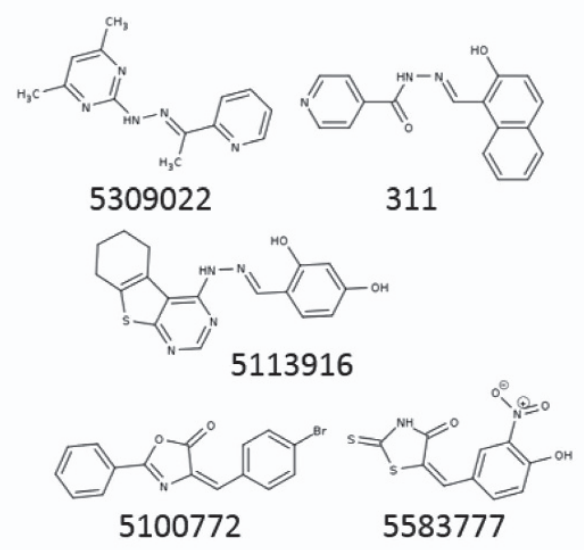

c

G2-phase network

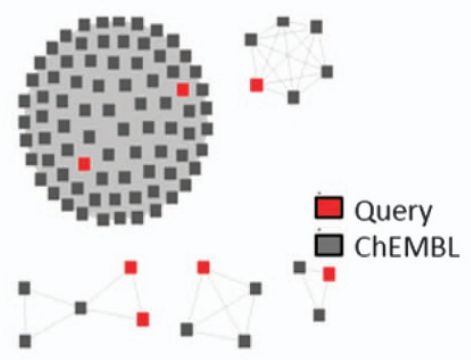

f G2 compound target inference
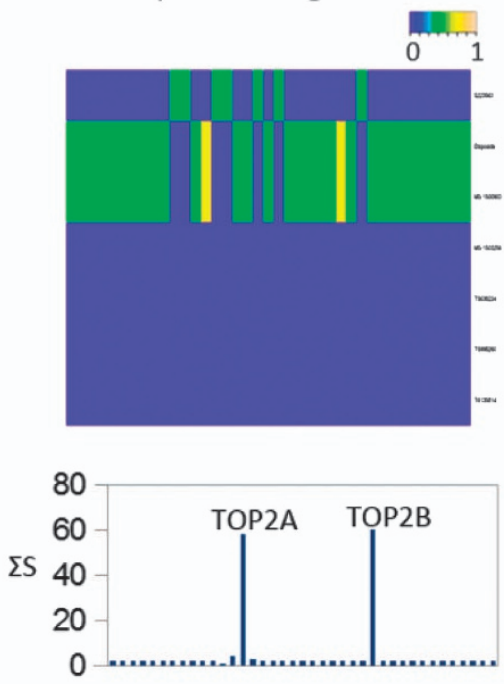

i

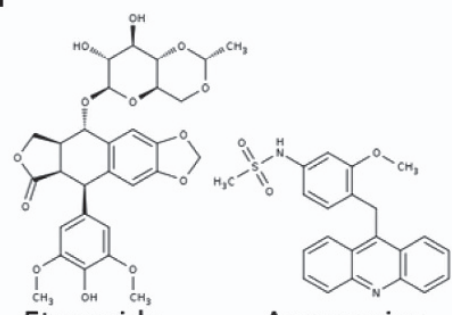

Figure 2 Deconvolving cell cycle modulators. (a-c) CSNAP network similarity graphs showing 64 G1 chemotypes, 68 S chemotypes, and 5 G2 chemotypes, respectively. Query compounds are in red and ChEMBL compounds are in gray. (d-f) CSNAP S-score function analyses and prediction of compound on/off-targets. Heatmap summaries of S-scores are scaled from 0-1. The cumulative S-score ( $\Sigma$ S-Score) of each assigned target in the target spectrum and the major predicted targets/off-targets are indicated. (g-i) Highlight of representative compounds within the top clusters for each cell cycle phase. (a-i) See also Supplementary Table 3 
(Mitotic Inhibitor 1-211) were tested for their ability to arrest cells in mitosis and to decrease cancer cell viability (Figure 3a). For mitotic arrest assays, HeLa cells were treated with a 20.2-fold-titration (190pM to $10 \mu \mathrm{M})$ of each compound for $20 \mathrm{~h}$ and the half maximal inhibitory concentration $\left(\mathrm{IC}_{50}\right)$ was derived for each compound using the cell cycle profile assay used in the initial screen (Figures $3 \mathrm{~b}$ and $\mathrm{c}$ and Supplementary Table 4). As an example, compound ASN05941236 displayed a mitotic arrest $I_{50}$ of $3.34 \mu \mathrm{M}$ (Figure 3b). Within the titration series, all compounds displayed a percent mitotic arrest between 48.3 and $83.6 \%$ (Figure 3d and Supplementary Table 4). For viability assays, cells were treated with a 14.2-fold-titration (12.2 nM to $100 \mu \mathrm{M})$ of each compound for $72 \mathrm{~h}$ and cell viability was measured using the CellTiter-Glo luminescent cell viability assay (Figures $3 e$ and $f$ and Supplementary Table 4). As an example, compound ASN05941236 displayed a cell death $\mathrm{IC}_{50}$ of $3.38 \mu \mathrm{M}$ (Figure $3 \mathrm{e}$ ). Interestingly, all 211 compounds arrested cells in mitosis and decreased cell viability (Supplementary Table 4). Most of these compounds were potent; 16 had a mitotic arrest $\mathrm{IC}_{50}$ of $\leq 100 \mathrm{nM}$, 56 had $\leq 500 \mathrm{nM}$, and $98 \mathrm{had} \leq 1 \mu \mathrm{M}$ (Figure $3 \mathrm{~g}$ and Supplementary Table 4). Similarly, 13 compounds had a cell viability $I C_{50}$ of $\leq 100 \mathrm{nM}, 56 \mathrm{had} \leq 500 \mathrm{nM}$, and $95 \mathrm{had} \leq 1 \mu \mathrm{M}$ (Figure $3 \mathrm{~h}$ and Supplementary Table 4).

Multiparametric phenotypic analyses of M-phase inhibitors. To investigate the mechanism of action of each anti-mitotic compound we performed high-resolution immunofluorescence (IF) microscopy to analyze the mitotic defects induced by these compounds (Figure 4). HeLa cells were treated with each of the 211 compounds at a concentration corresponding to their mitotic arrest $I \mathrm{C}_{90}$ for $20 \mathrm{~h}$. Cells were then fixed, permeabilized, and co-stained for DNA and $a$-tubulin. Six major classes of phenotypes were observed: multipolar spindle, normal bipolar spindle with unaligned chromosomes, defective bipolar spindle with unaligned chromosomes, mixed phenotype (containing more than one of the six phenotypes), depolymerized microtubules, and stabilized microtubules (Figure 4a and Supplementary Table 4). a

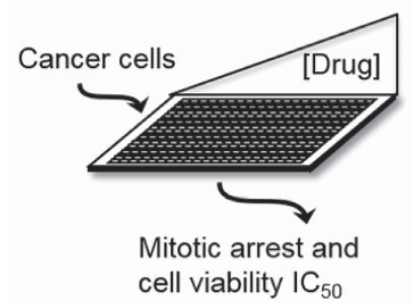

d

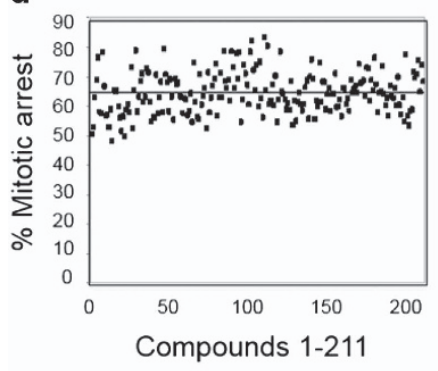

b

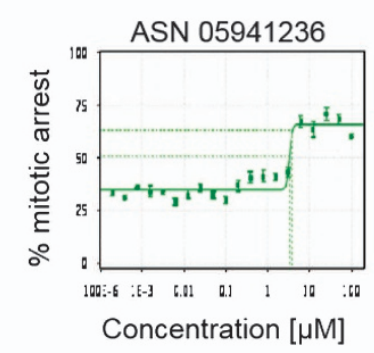

e

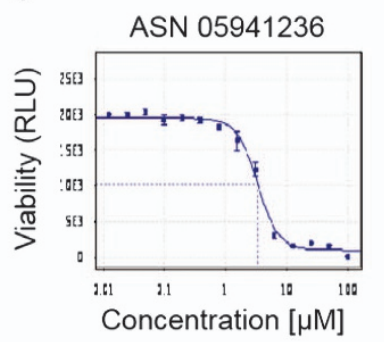

c

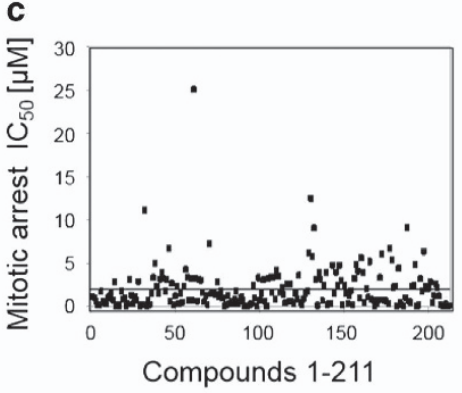

f

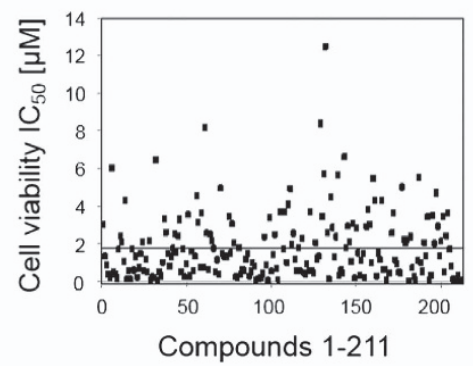

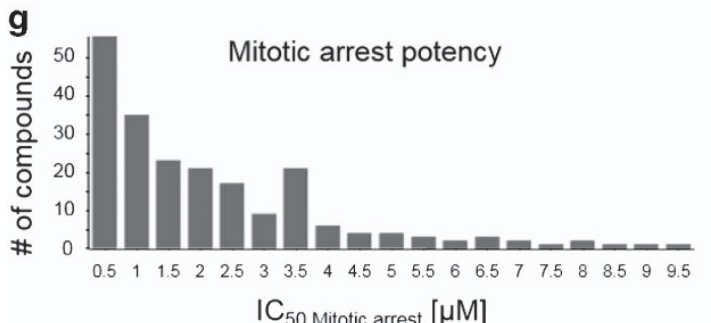

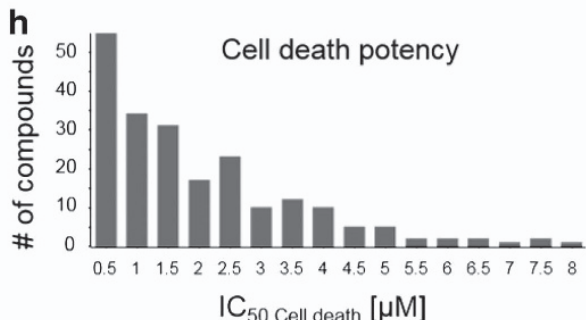

Figure 3 Anti-mitotic compound potency. (a) Determination of compound mitotic arrest and cell viability $I C_{50}$. HeLa cells were treated with increasing concentrations of each compound for 20 or $72 \mathrm{~h}$ and assayed for mitotic arrest and cell viability, respectively. (b) Example of mitotic arrest I $\mathrm{C}_{50}$ curve. $x$-axis is drug concentration in $\mu \mathrm{M}$ scale and $y$-axis is percent cells arrested in mitosis. (c) Scatter plot of mitotic arrest $I \mathrm{C}_{50}$ in $\mu \mathrm{M}$ scale ( $y$-axis) for all mitotic compounds ( $x$-axis). (d) Scatter plot of the percent mitotic arrest $I C_{50}$ in $\mu \mathrm{M}$ scale ( $y$-axis) for all mitotic compounds ( $x$-axis). (e) Example of the cell viability $I C_{50}$ curve. $x$-axis is drug concentration in $\mu \mathrm{M}$ scale and $y$-axis represents cell viability in relative light units (RLU). (f) Scatter plot of the cell viability $I_{50}$ in $\mu \mathrm{M}$ scale ( $y$-axis) for all mitotic compounds $(x$-axis). $(\mathbf{g}, \mathbf{h})$ Summary graphs of mitotic arrest and cell death potency for all compounds. $x$-axis is drug concentration in $\mu \mathrm{M}$ scale and $y$-axis represents the number of compounds within each category. Note that 56 compounds showed a mitotic arrest $\mathrm{IC}_{50}$ below $500 \mathrm{nM}$. (b-h) See also Supplementary Table 4 
a

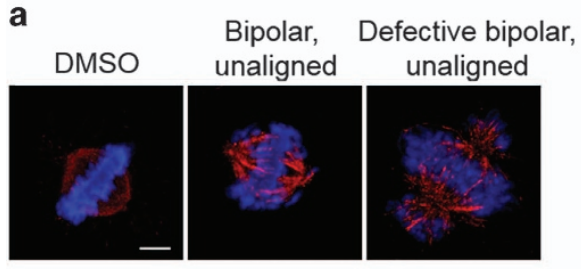

b

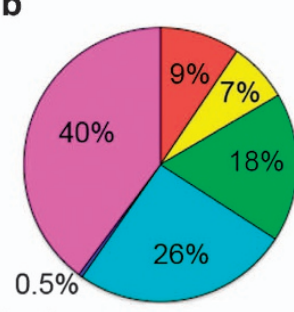

Mixed

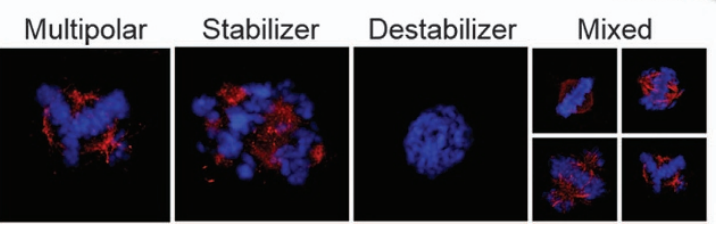

Figure 4 High-resolution phenotypic analysis of mitotic inhibitors. (a) Summary of the six phenotype classes observed upon treatment with Ml-1 through MI-211: bipolar spindle with unaligned chromosomes, defective bipolar spindle with unaligned chromosomes, multipolar spindle, mixed phenotype, depolymerized microtubules, and stabilized microtubules; imaged by immunofluorescence microscopy. Cells were treated with compounds for $20 \mathrm{~h}$, fixed, and co-stained for $\alpha$-tubulin (anti-tubulin antibodies, red) and DNA (Hoechst 33342, blue). Bar indicates $5 \mu \mathrm{m}$. (b) Summary of the percentage of the total M-phase inhibitors in each phenotypic category. See also Supplementary Table 4

The compound class that induced microtubule depolymerization was the most abundant with 84 compounds falling into this category, followed by the mixed phenotype (54 compounds) and the multipolar phenotype (37 compounds) (Figure 4b and Supplementary Table 4).

Selection of MI-181 as a lead compound. To aid the selection of lead compounds to pursue for further characterization, we performed a clustering analysis of the compounds and their bioactive properties, including mitotic arrest $\mathrm{IC}_{50}$, cell death $\mathrm{IC}_{50}$, phenotypic class of mitotic arrest, and percentage of cells arrested in mitosis (Figure 5a). This analysis revealed that $\mathrm{Ml}-181$ was the most potent (mitotic arrest $\mathrm{IC}_{50}=23 \mathrm{nM}$ and cell death $\mathrm{IC}_{50}=17 \mathrm{nM}$ ) compound, similar to the taxol (mitotic arrest $I_{50}=37 \mathrm{nM}$ and cell death $I_{50}=27 \mathrm{nM}$ ) and colchicine (mitotic arrest $I_{50}=24 \mathrm{nM}$ and cell death $\mathrm{IC}_{50}=12 \mathrm{nM}$ ) controls (Figure $5 \mathrm{a}$ and Supplementary Figures 1 and 2). In addition, Ml-181 arrested more cells in mitosis compared with colchicine and taxol, $77 \%$ versus $76 \%$, and $74 \%$, respectively (Supplementary Table 4). Ml-181 is a small (266Da) synthetic benzothiazolebased compound, and in silico analysis of its physiochemical properties indicated that it conformed to parameters needed for oral bioavailability in humans ${ }^{16}$ (Figure $5 b$ and Supplementary Figure 3). Unsurprisingly a substructure search for FDA-approved benzothiazole-based and structurally related benzimidazole-based drugs revealed 8 benzothiazole-based drugs and 10 benzimidazole-based drugs approved for various clinical uses (Supplementary Figure 4). For example, benzothiazoles included the vasodilator Fostedil and a tetrodotoxin-sensitive sodium channel blocker Riluzole approved for the treatment of heart disease and amyotrophic lateral sclerosis, respectively (Supplementary Figure 4). ${ }^{35-38}$ Whereas benzimidazoles included inhibitors of tubulin polymerization like nocodazole and mebendazole approved for the treatment of neoplasms and warm infestations (Supplementary Figure 4)..$^{39,40}$ Thus benzothiazoles that inhibit tubulin polymerization, like Ml-181, have potential for clinical use. Although the benzothiazole and benzimidazole substructures share strong chemical similarity, the chemical diversity of FDA-approved drugs with these substructures is diverse, indicating that these substructures have been effectively used as scaffolds for generating specificity to various cellular targets for the treatment of various diseases (Supplementary Figure 4).

MI-181 inhibits tubulin polymerization. To evaluate MI-181's mechanism of action, we treated HeLa cells with Ml-181 for $20 \mathrm{~h}$, fixed them, co-stained them for DNA and atubulin, and imaged them by IF microscopy (Figure $5 \mathrm{c}$ ). These analyses revealed that $\mathrm{Ml}-181$-treated cells failed to form a mitotic spindle and only small tubulin puncta were observed, indicative of microtubule depolymerization (Figure $5 \mathrm{c}$ ). This was further confirmed in vitro where Ml-181 inhibited tubulin polymerization in an in vitro tubulin polymerization assay, similar to colchicine (Figure $5 d$ ).

MI-181 arrests cells in mitosis, activates the SAC, and triggers cell death. To explore the nature of the Ml-181induced mitotic arrest, we asked if it was activating the spindle assembly checkpoint (SAC) to arrest cells in mitosis. First, we confirmed that $\mathrm{Ml}-181$ was indeed arresting cells in mitosis. HeLa cells were treated with DMSO, MI-181, or colchicine for $18 \mathrm{~h}$, cells were fixed, co-stained for DNA, microtubules, kinetochores, and the mitotic marker $\mathrm{p}-\mathrm{H} 3$, and imaged by fluorescence microscopy. Similar to colchicine treatment, Ml-181 treatment arrested cells in mitosis with p-H3-positive staining and unaligned tightly condensed chromosomes (Figure 5e). Next, we asked if the SAC was activated in these cells by co-staining for the SAC component Bub1. Indeed, Bub1 remained localized to the kinetochore region in colchicine-and $\mathrm{Ml}$-181-treated cells (Figure 5f). Similarly, in cells co-stained for the SAC kinase AurKB, AurKB remained localized to the kinetochore region and never transitioned to the central spindle as in control DMSOtreated cells (Figure $5 \mathrm{~g}$ ). These data indicated that MI-181treated cells were arrested in early mitosis with an active SAC. To further validate this, cells were synchronized in 
a

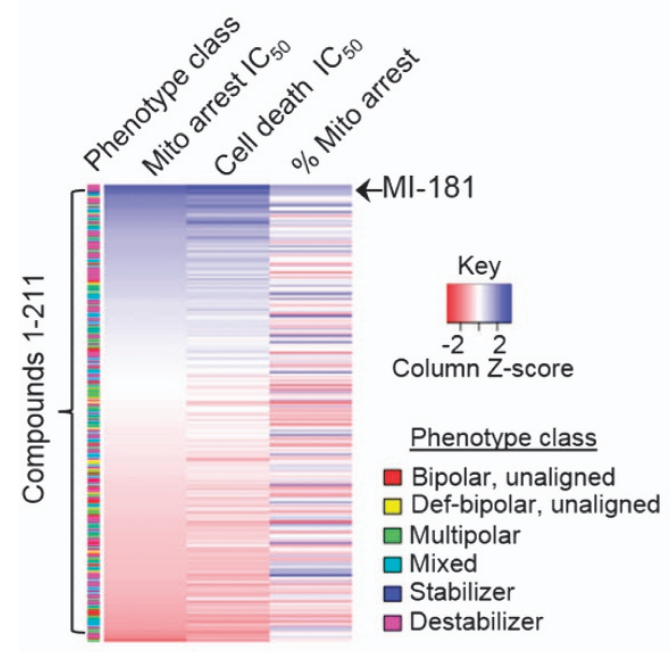

b

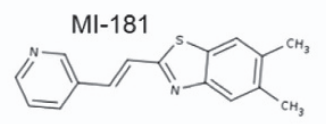

C

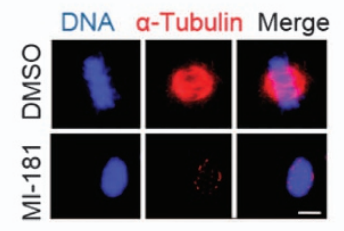

d

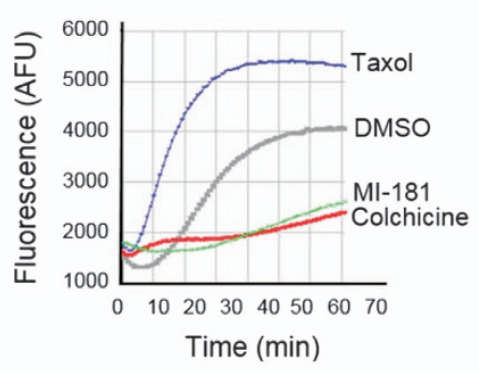

e

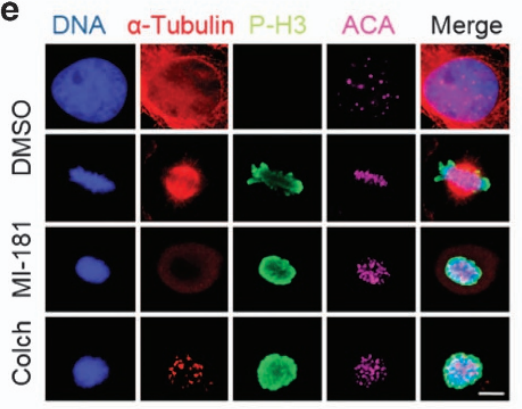

g

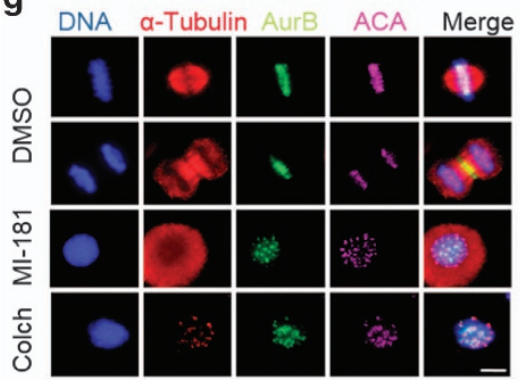

$\mathbf{f}$

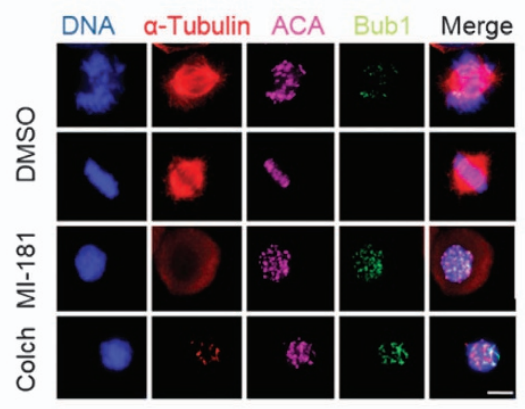

h

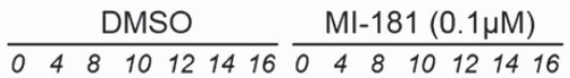

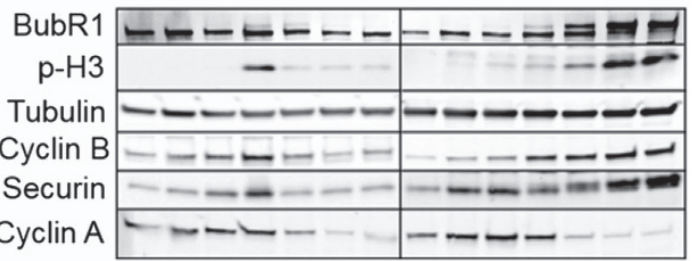

Figure 5 Selection of lead compound Ml-181. (a) Clustering of 211 M-phase compounds based on their bioactive properties. For each compound the following data were grouped and the compounds were sorted based on mitotic arrest I $\mathrm{C}_{50}$ : phenotype class, mitotic arrest I $\mathrm{C}_{50}$, cell death $\mathrm{IC}_{50}$, and percent mitotic arrest. Note that MI-181 was the most potent inhibitor (mitotic arrest IC ${ }_{50}=24 \mathrm{nM}$ ). (b) Chemical structure of Ml-181. (c) Cells were treated with DMSO or Ml-181 for $20 \mathrm{~h}$, fixed, co-stained for DNA (Hoechst 33342) and microtubules (anti- $\alpha$-Tubulin antibodies), and imaged by immunofluorescence (IF) microscopy. Images show that MI-181-treated cells arrest with condensed chromosomes and depolymerized microtubules. (d) Results from in vitro tubulin polymerization reactions in the presence or absence of DMSO, MI-181, colchicine, and taxol. Note that MI-181 inhibits tubulin polymerization. (e-g) IF microscopy showing that MI-181-treated cells arrest in mitosis ( $\mathrm{p}$-H3 positive) (e) and activate the SAC (Bub1 remains at the kinetochore region (f) and AurKB remains on chromosomes and kinetochores and does not transition to the central spindle $(\mathbf{g})$ ). (h) Immunoblot analysis of extracts prepared from DMSO or Ml-181-treated cells, which were synchronized in G1/S and released into the cell cycle. Note that cyclin A levels decrease as cells enter mitosis concomitant with an increase in $\mathrm{p}-\mathrm{H} 3$ signal, and cyclin B, while BubR1 remains phosphorylated only in Ml-181-treated cells, indicative of an active spindle assembly checkpoint. (c, e-g) Bar indicates $5 \mu \mathrm{m}$

G1/S, released into the cell cycle in the presence of DMSO or $\mathrm{Ml}-181$ and cell extracts were prepared at several time points post release. Consistent with our fixed-cell IF results, immunoblot analysis of these extracts revealed that MI-181treated cells arrested in mitosis ( $\mathrm{p}-\mathrm{H} 3$ positive), activated the SAC (BubR1 remained phosphorylated), and stabilized cyclin
B while degrading cyclin A (Figure 5h). In addition, the Ml-181-induced mitotic arrest was reversible, as cells exited mitosis within $2 \mathrm{~h}$ of drug washout (Supplementary Figure 5).

To further analyze the cellular consequences of treating cancer cells with Ml-181, we coupled cell synchronization with live-cell time-lapse IF microscopy. Synchronized HeLa 
a

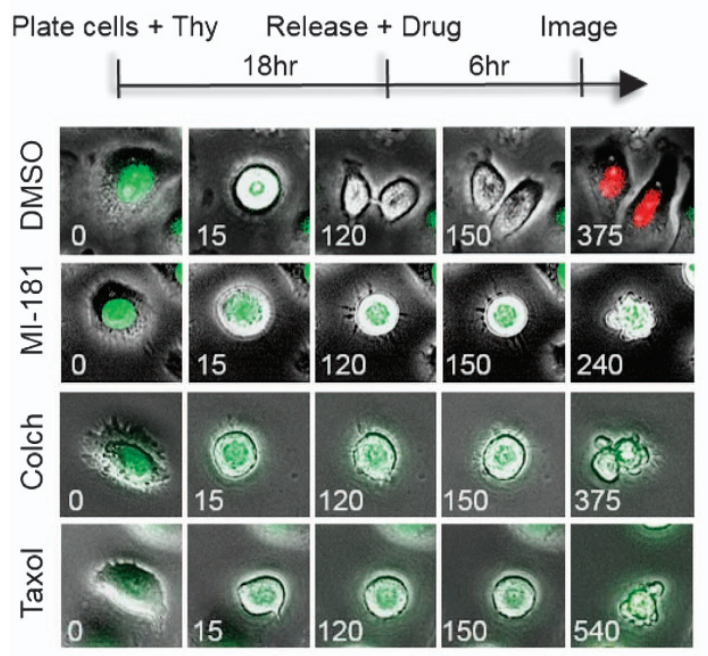

b
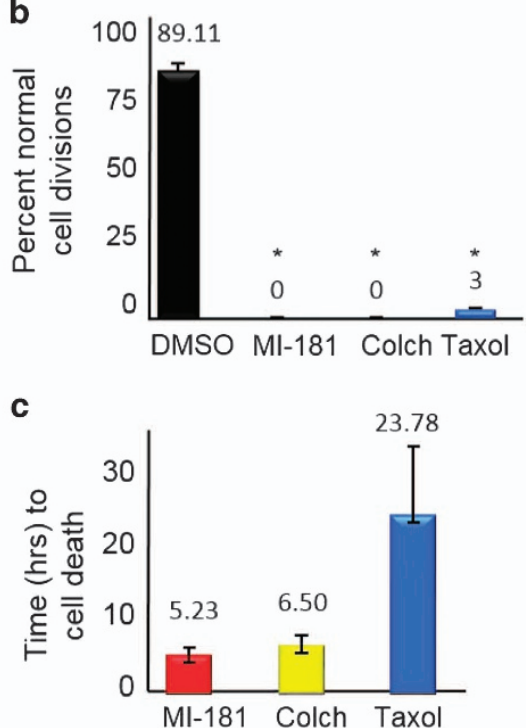

Figure 6 Ml-181 is a potent cell division inhibitor. (a) Live-cell time-lapse microscopy of HeLa FUCCI cells treated with DMSO, Ml-181, colchicine, or taxol. Time is in minutes. (b) The percentage of cells undergoing normal cell division was quantified for DMSO, Ml-181, colchicine, or taxol-treated cells. Asterisk denotes $P$-value $<0.0001$. (c) The time from mitotic entry to cell death was quantified for DMSO-, Ml-181-, colchicine-, or taxol-treated cells. Error bars indicate \pm S.D. from the mean

fluorescent ubiquitination-based cell cycle (FUCCI) indicator cell line cells were treated with DMSO, MI-181, colchicine, or taxol 2 hours prior to mitotic entry and their effect on mitosis was assessed ${ }^{41}$ (Figure 6a). Images were captured at 15-min intervals and processed into movie format (Figure 6a and Supplementary Movies 1). The movies were then analyzed to determine the percentage of cells with a defective mitosis and the length of time between mitotic entry and cell death ${ }^{42}$ (Figures $6 \mathrm{~b}$ and $\mathrm{c}$ ). Whereas control DMSO-treated cells transitioned through mitosis (green fluorescence) and into G1 (red fluorescence) normally, Ml-181-treated cells arrested in mitosis and failed to divide similar to colchicine- and taxol-treated cells ( $\%$ normal cell divisions for $\mathrm{Ml}-181=0$, $P<0.0001$; colchicine $=0, P<0.0001$; taxol $=3 \pm 0.8, P<0.0001$; compared with $\mathrm{DMSO}=89.11 \pm 2.9$ ) (Figure $6 \mathrm{~b}$ ). Although individual cell responses to drugs differed widely, colchicine-and $\mathrm{Ml}$-181-treated cells arrested for a shorter time-length than taxol prior to apoptosing (Ml-181= $5.3 \pm 0.96 \mathrm{~h}$, colchicine $=6.2 \pm 1.27 \mathrm{~h}$, compared with taxol $=23.78 \pm 9.03 \mathrm{~h}$ ) (Figure $6 \mathrm{c}$ ). These data indicated that Ml-181 was a potent cell cycle-specific inhibitor, which arrested cells in mitosis, activated the SAC, and induced an apoptotic cell death with faster kinetics than taxol.

Ml-181 is active in a broad array of cancers, especially melanomas. To determine if $\mathrm{Ml}-181$ had broad anti-cancer activity, we treated a diverse panel of cancer cell lines including cervical adenocarcinoma (HeLa), breast adenocarcinoma (MCF7), melanoma (M233), osteosarcoma (U2OS), acute lymphoblastic leukemia (CCRF-CEM), non-small cell lung carcinoma ( $\mathrm{NCl}-\mathrm{H} 460)$, and breast adenocarcinoma (MCF7) with $\mathrm{MI}-181$ and determined its cell viability $\mathrm{IC}_{50}$ (Figures $7 \mathrm{a}$ and b). Interestingly, MI-181 showed great efficacy across most cancer cell lines with a cell viability $\mathrm{IC}_{50}$ ranging from 0.03 to $0.36 \mu \mathrm{M}$, with the exception of
MCF7 cells $\left(\mathrm{IC}_{50}=11 \mu \mathrm{M}\right)$ (Figures $7 \mathrm{a}$ and $\left.\mathrm{b}\right)$. These results indicated that $\mathrm{Ml}-181$ was potent across a broad array of cancers and was most effective against cervical adenocarcinoma and melanoma cell lines. Therefore, we analyzed the efficacy of $\mathrm{Ml}-181$ in a panel of melanoma cell lines with defined genetic backgrounds including BRAF $^{\text {V6OOE }}$ and NRAS ${ }^{Q 61 L}$ mutations and varied sensitivities to Vemurafenib (BRAF inhibitor) and Trametinib (MEK inhibitor), which are currently used to treat BRAF $^{\text {V6OOE }}$ melanomas ${ }^{43,44}$ (Figure 7c). Ml-181 displayed great potency across this panel $\left(\mathrm{IC}_{50}=18-90 \mathrm{nM}\right)$ (Figure 7c and Supplementary Table 5). As a general trend BRAF ${ }^{V 600 E}$ cell lines were slightly more sensitive than NRAS ${ }^{Q 61 L}$ cell lines and Ml-181 was effective in Vemurafenib- and Trametinib-resistant cell lines (Figure 7c and Supplementary Table 5). Finally, we tested the ability of $\mathrm{Ml}-181$ to inhibit melanoma colony formation using the M233 and M308 cell lines (both resistant to Vemurafenib). Indeed, $\mathrm{Ml}-181$ was a potent inhibitor of colony formation (percentage

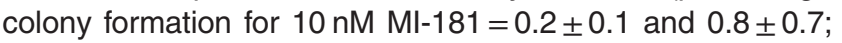
for $10 \mathrm{nM}$ colchicine $=0.1 \pm 0.06$ and $1.5 \pm 0.5$; and for $10 \mathrm{nM}$ Vemurafenib = 94 \pm 7 and $102 \pm 5$ ) (Figure 7d). Thus, MI-181 is a potent inhibitor of melanoma cell lines.

\section{Discussion}

Chemical inhibition of the cell cycle and cell division has been a fruitful approach for understanding the mechanisms that cancer cells rely on to proliferate and for the development of therapeutics to inhibit these processes. Previous studies taking unbiased chemical screening approaches to identify anti-proliferative agents were limited by screening assay output, chemical library composition, lack of chemical analysis on hits, and a narrow focus on specific phases of the cell cycle. Here, we devised a cell cycle profiling high-throughput chemical screening approach that enabled the identification 

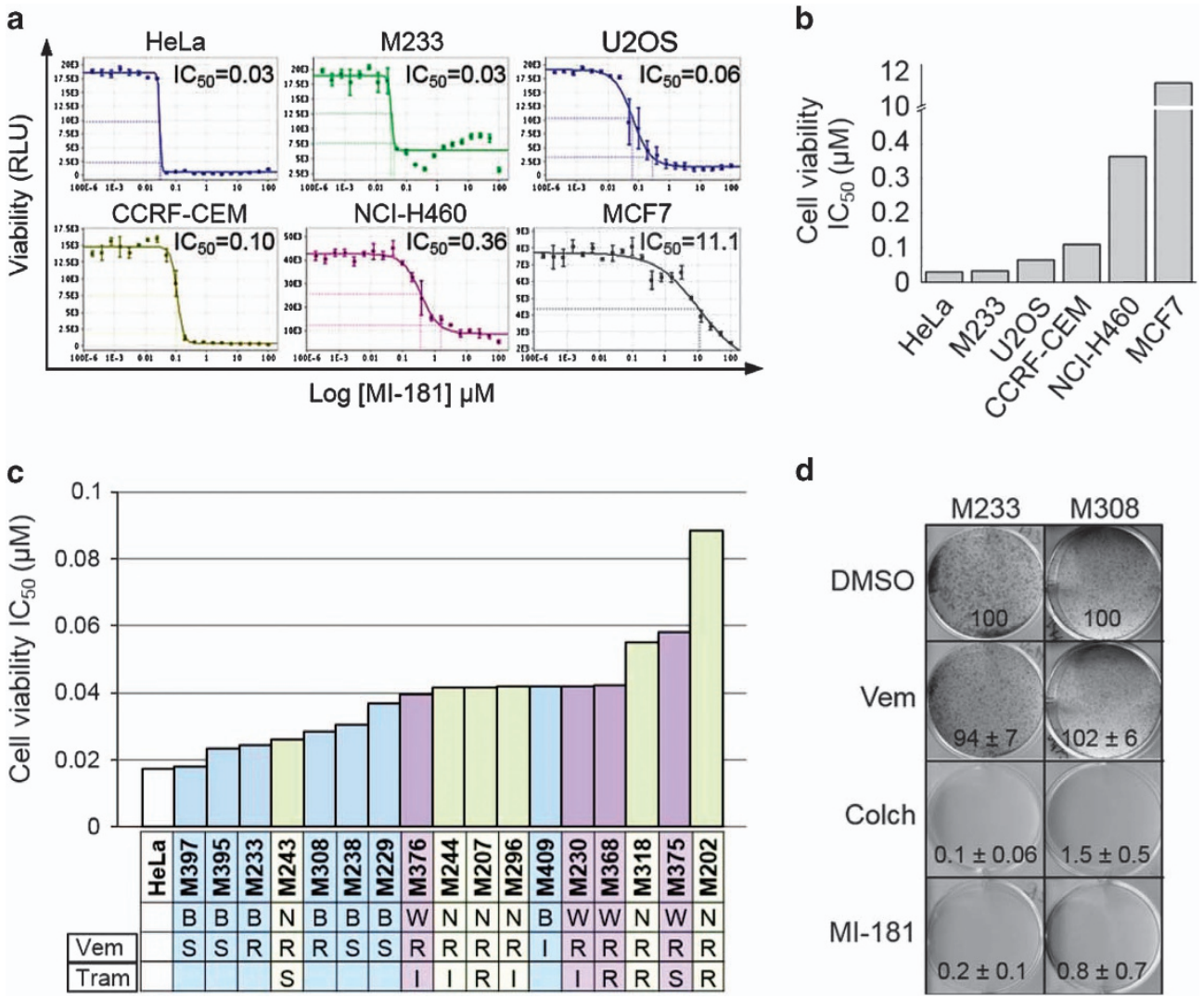

Figure 7 Ml-181 is a potent cancer cell division inhibitor, especially melanomas. (a, b) Ml-181 is potent against a broad panel of cancer cell lines. Cervical adenocarcinoma (HeLa), breast adenocarcinoma (MCF7), melanoma (M233), osteosarcoma (U2OS), acute lymphoblastic leukemia (CCRF-CEM), non-small cell lung carcinoma (NCI-H460), and breast adenocarcinoma (MCF7) cells were treated with increasing concentrations of MI-181 (190pM-10 $\mu \mathrm{M})$ for $72 \mathrm{~h}$ and their cell viability $\mathrm{IC}_{50}$ was assessed using the CellTiterGlo assay. (c) A panel of melanoma cells were treated with increasing concentrations of $\mathrm{Ml}-181$ and the $\mathrm{IC}_{50}$ was determined for each cell line as described in a. B, BRAF ${ }^{\mathrm{V} 600 E}$; N, NRAS ${ }^{\text {Q61L; }}$ R, resistant; S, sensitive; Tram, Trametinib; Vem,Vemurafenib; W, wildtype. (d) Ml-181 inhibits melanoma colony formation. M233 and M308 melanoma cells were treated with DMSO, Vemurafenib $(1 \mu \mathrm{M})$, colchicine $(100 \mathrm{nM})$, or Ml-181 (100 nM) for 7 days and the percent colony formation, normalized to DMSO, was quantified. Percent colony formation and standard deviation are indicated at the bottom of each panel for each drug and cell line

of cell cycle modulators specifically inhibiting G1, S, G2, and M-phases while avoiding the difficulties associated with highthroughput fluorescence activated cell sorting screening. The utility of this approach was validated by the identification of well-validated cell cycle-specific inhibitors and their analogs. Most importantly, this screen uncovered numerous novel compounds representing variable chemotypes, which warrant further validation and characterization as anti-cancer agents.

In our approach, the use of computational chemoinformatics enabled the generation of hit compound network similarity graphs that grouped compounds based on chemotypes, facilitated compound target and off-target prediction, and identified analogs of validated inhibitors with the potential to be more potent, more specific, or less toxic. The wealth of information derived from these computational analyses could aid future studies aimed at discovering/developing anti-cancer agents. Thus, we propose that similar chemical deconvolution approaches be part of every future high-throughput chemical screen. Similarly, the characterization of compounds based on potency and multiparametric phenotypic analysis adds valuable information to the selection of lead compounds for the purposes of being used as chemical probes to dissect the mechanisms driving the cell cycle, as anti-cancer agents, or both and should be considered an integral part of cell-based chemical screening campaigns.

The chemical diversity of the mitotic inhibitors and the array of mitotic defects induced by these compounds indicate that they are likely targeting a broad array of mitotic targets. Therefore, these inhibitors could be used to study the function of these targets in an acute and temporal manner and they warrant further evaluation and target identification/validation. The selection of Ml-181 as a lead anti-cancer compound in our study highlights the utility of cell-based chemical screening for the identification of potent cell permeable drug-like phase specific drugs. MI-181 targets tubulin, inhibits tubulin polymerization, activates the SAC, arrests cells in mitosis, and triggers an apoptotic cell death. Most importantly, Ml-181 has broad anti-cancer activity and is especially potent against melanomas.

Microtubule depolymerizers like vinblastine and vincristine are currently in clinical use for the treatment of testicular cancer, lung cancer, leukemias, and lymphomas ${ }^{45}$ and there is a critical need to identify novel synthetic molecules that can address the limitations of these drugs (synthesis, toxicity, resistance, and so on). Thus, Ml-181 represents an opportunity to develop improved alternatives to these drugs. 


\section{Materials and Methods}

Cell culture. Non-melanoma cell lines were purchased from ATCC (Manassas, VA, USA), which verified identity by short-tandem repeat profiling, and were passaged for $<6$ months following receipt and were maintained in F12: DMEM 50 : 50 medium (GIBCO, Grand Island, NY, USA) with 10\% FBS, $2 \mathrm{mM}$ L-glutamine, and antibiotics, in $5 \% \mathrm{CO}_{2}$ at $37^{\circ} \mathrm{C}$. Melanoma cell lines were established from patient biopsies under UCLA IRB approval \#02-08-067, as described previously. ${ }^{46}$ Melanoma cell lines were genotyped using Oncomap3 platform for 33 genes, Affymetrix Gene Chip for SNP and lonTorrent for nextgeneration sequencing, and were passaged for $<6$ months following verification, and were maintained in RPMI (GIBCO) with $10 \% \mathrm{FBS}$ and antibiotics in $5 \% \mathrm{CO}_{2}$ at $37^{\circ} \mathrm{C}$, as described previously. ${ }^{46}$ For $\mathrm{G} 1 / \mathrm{S}$ arrests, cells were treated with $2 \mathrm{mM}$ thymidine (Sigma-Aldrich, St. Louis, MO, USA) for $18 \mathrm{~h}$.

High-throughput cell cycle modulator assay. HeLa cells were plated in 384-well plates (1500 cells/well) and treated with $10 \mu \mathrm{M}$ drugs for $20 \mathrm{~h}$. Cells were fixed and stained with $5 \mu \mathrm{M}$ Vybrant DyeCycle Green (Invitrogen, Grand Island, NY, USA) for $1 \mathrm{~h}$ at room temperature and plates were scanned with an Acumen eX3 (TTP Labtech, Cambridge, MA, USA) fluorescence cytometer using its $488 \mathrm{~nm}$ laser and a cell cycle histogram profile was generated for each well. For the G2/M secondary screen, $20 \mathrm{~h}$ post drug addition cells were fixed with $4 \%$ paraformaldehyde, permeabilized with $0.2 \%$ Triton X-100/PBS, and stained with Alexa-488-phospho-histone-H3 (Ser10, Cell Signaling, Danvers, MA, USA) and $1 \mu \mathrm{g} / \mathrm{ml}$ Hoechst 33342 for $1 \mathrm{~h}$. Plates were imaged with an ImageXpress Micro (Molecular Devices, Sunnyvale, CA, USA) high-content fluorescence microscope. Data analysis was performed using the Collaborative Drug Discovery (CDD, Burlingame, CA, USA; www.collaborativedrug.com) software and outputs were exported to Excel. The quality of the screen was assessed by calculating the $Z^{\prime}$ factor $\left(Z^{\prime}\right.$ factor $\left.=1-3 \times\left(\sigma_{\mathrm{p}}+\sigma_{\mathrm{n}}\right) /\left(\mu_{\mathrm{p}}-\mu_{\mathrm{n}}\right)\right)$ ), which takes into account the dynamic range of the assay and variance of the data. ${ }^{47}$ The screen performed with an average plate $Z^{\prime}$ factor of $0.51 \pm 0.09$, within the optimal performance range of $0.5-1 .{ }^{47}$

Compound potency. For mitotic arrest $\mathrm{IC}_{50} \mathrm{~S}$, cells were treated with a 20.2fold-titration (190pM to $10 \mu \mathrm{M}$ ) of each compound for $20 \mathrm{~h}$. For cell viability $I_{50} \mathrm{~S}$, cells were treated with a 14.2 -fold-titration $(12.2 \mathrm{nM}$ to $100 \mu \mathrm{M})$. Mitotic arrest IC 50 was determined by measuring the percent G2/M arrest using the Vybrant DyeCycle Green (Invitrogen) assay described above. Cell viability $I_{50}$ was determined using the CellTiter-Glo Assay (Promega, Madison, WI, USA), which measures total ATP levels. Plates were read with a Tecan M1000 micro-plate reader (Tecan, San Jose, CA, USA) at $540 \mathrm{~nm}$. The CDD software (Burlingame, CA, USA, www. collaborativedrug.com) was used for generating $\mathrm{IC}_{50}$ and $\mathrm{IC}_{90}$ values.

IF and time-lapse microscopy. IF microscopy was carried out as described previously. ${ }^{48}$ Except that images were captured with a Leica DMI6000 microscope (Leica Microsystems, Buffalo Grove, IL, USA) and deconvolved with Leica deconvolution software. Time-lapse microscopy was performed as described previously. ${ }^{18}$ Briefly, HeLa FUCCI (where $S$ through M-phase cells are green due to expression of the mAG-hGeminin fusion protein, and G1-phase cells are red due to expression of the $\mathrm{mKO} 2$-hCdt1 fusion protein) cells were released from $\mathrm{G} 1 / \mathrm{S}$ in the presence of indicated drug or control DMSO, and ten Z-stack images $(0.9 \mu \mathrm{m}$ steps) were captured $6 \mathrm{~h}$ post release at 15-min intervals. Images were deconvolved and converted to AVI movie files.

CSNAP chemical analysis. CSNAP was used to predict the targets of G1, S, and G2-phase inhibitors as described previously. Briefly, compounds were queried in the annotated ChEMBL database version 18 (The EMBL-European Bioinformatics Institute, Cambridge, UK) using the following search parameters: tanimoto cutoff $=0.75, Z$-score cutoff $=2.5$. The ChEMBL target annotations were retrieved from the database based on the following criteria: confidence score $=4$, assay-type $=$ binding. Finally, chemical similarity networks and ligand-target interaction fingerprint analyses were analyzed using Cytoscape (Cytoscape Consortium, San Diego, CA, USA; www.cytoscape.org) and the R statistical package (R Foundation Institute for Statistics and Mathematics, Wien, Austria; www.www.r-project.org), respectively.

Clonogenic assays. M233 and M308 melanoma cells were seeded at 15000 cells/well in six-well plates. The next day, cells were treated with indicated drugs or
DMSO. Seven days post incubation, cells were fixed with $4 \%$ paraformaldehyde, stained with $0.05 \%$ Crystal violet, and colonies were counted for each treatment.

In vitro tubulin polymerization assays. Tubulin polymerization reactions were carried out according to the manufacturer (BK011P, Cytoskeleton, Denver, CO, USA) in the presence of $3 \mu \mathrm{M}$ colchicine, Ml-181, taxol, or DMSO. Polymerization was monitored with a Tecan M1000 micro-plate reader (Tecan) at $420 \mathrm{~nm}$ for $70 \mathrm{~min}$ at $37^{\circ} \mathrm{C}$.

Antibodies. Phospho-histone-H3-488 (Cell Signaling), Phospho-histone-H3 ( $\mathrm{p}$-H3, Millipore, Billerica, MA, USA) $\alpha$-tubulin (Serotec, Raleigh, NC, USA), AurKB (BD Transduction, San Jose, CA, USA), Anti-Centromere-Antibodies (ACA, Cortex Biochem, Madison, WI, USA), cyclin A and B (Santa Cruz Biotechnology, Dallas, TX, USA), and SECURIN (Gene Tex, Irvine, CA, USA). BubR1 and Bub1 were from Hongtao Yu. FITC-, Cy3-, and Cy5-conjugated secondary antibodies were from Jackson Immuno Research.

\section{Conflict of Interest}

The authors declare no conflict of interest.

Acknowledgements. Research reported in this publication includes work performed in the Molecular Screening Shared Resource supported by the National Cancer Institute of the National Institutes of Health under award number P30CA016042. The content is solely the responsibility of the authors and does not necessarily represent the official views of the National Institutes of Health. This work was supported by a Jonsson Cancer Center Foundation seed grant, The V Foundation for Cancer Research V Scholar Award, the University of California Cancer Research Coordinating Committee Funds, and a National Science Foundation Grant NSF-MCB1243645 to JZT; a NIH K25CA157940 award to TAZ; NIH R01CA185189, R01CA90571, R01CA156674, R01GM073981, and P01GM081621 awards to MAT; a $\mathrm{NIH}$ P01CA168585 to AR; LR was supported by the V Foundation-Gil Nickel Family Endowed Fellowship in Melanoma Research and a grant from the Spanish Society of Medical Oncology (SEOM) for Translational Research in Reference Centers.

1. Schwartz GK, Shah MA. Targeting the cell cycle: a new approach to cancer therapy. J Clin Oncol 2005; 23: 9408-9421.

2. Williams GH, Stoeber K. The cell cycle and cancer. J Pathol 2012; 226: 352-364.

3. Manchado E, Guillamot M, Malumbres M. Killing cells by targeting mitosis. Cell Death Differ 2012; 19: 369-377.

4. Komlodi-Pasztor E, Sackett DL, Fojo AT. Inhibitors targeting mitosis: tales of how great drugs against a promising target were brought down by a flawed rationale. Clin Cancer Res 2012; 18: $51-63$.

5. Neumann B, Walter T, Heriche JK, Bulkescher J, Erfle H, Conrad C et al. Phenotypic profiling of the human genome by time-lapse microscopy reveals cell division genes. Nature 2010; 464: 721-727.

6. Steegmaier M, Hoffmann M, Baum A, Lenart P, Petronczki M, Krssak M et al. BI 2536, a potent and selective inhibitor of polo-like kinase 1, inhibits tumor growth in vivo. Curr Biol 2007; 17: 316-322.

7. Lenart P, Petronczki M, Steegmaier M, Di Fiore B, Lipp JJ, Hoffmann M et al. The smallmolecule inhibitor BI 2536 reveals novel insights into mitotic roles of polo-like kinase 1. Curr Biol 2007; 17: 304-315.

8. Hoelder S, Clarke PA, Workman P. Discovery of small molecule cancer drugs: successes, challenges and opportunities. Mol Oncol 2012; 6: 155-176.

9. Castoreno AB, Smurnyy Y, Torres AD, Vokes MS, Jones TR, Carpenter AE et al. Small molecules discovered in a pathway screen target the Rho pathway in cytokinesis. Nat Chem Biol 2010; 6: 457-463.

10. Haggarty SJ, Mayer TU, Miyamoto DT, Fathi R, King RW, Mitchison TJ et al. Dissecting cellular processes using small molecules: identification of colchicine-like, taxol-like and other small molecules that perturb mitosis. Chem Biol 2000; 7: 275-286.

11. Mayer TU, Kapoor TM, Haggarty SJ, King RW, Schreiber SL, Mitchison TJ. Small molecule inhibitor of mitotic spindle bipolarity identified in a phenotype-based screen. Science 1999; 286: 971-974.

12. Murphey RD, Stern HM, Straub CT, Zon LI. A chemical genetic screen for cell cycle inhibitors in zebrafish embryos. Chem Biol Drug Des 2006; 68: 213-219.

13. Peters U, Cherian J, Kim JH, Kwok BH, Kapoor TM. Probing cell-division phenotype space and Polo-like kinase function using small molecules. Nat Chem Biol 2006; 2: 618-626.

14. Roberge M, Berlinck RG, Xu L, Anderson HJ, Lim LY, Curman D et al. High-throughput assay for G2 checkpoint inhibitors and identification of the structurally novel compound isogranulatimide. Cancer Res 1998; 58: 5701-5706. 
15. Wilson CJ, Si Y, Thompsons CM, Smellie A, Ashwell MA, Liu JF et al. Identification of a small molecule that induces mitotic arrest using a simplified high-content screening assay and data analysis method. J Biomol Screen 2006; 11: 21-28.

16. Lipinski CA. Drug-like properties and the causes of poor solubility and poor permeability. J Pharmacol Toxicol Methods 2000; 44: 235-249.

17. Jeon JY, An JH, Kim SU, Park HG, Lee MA. Migration of human neural stem cells toward an intracranial glioma. Exp Mol Med 2008; 40: 84-91.

18. Torres JZ, Summers MK, Peterson D, Brauer MJ, Lee J, Senese S et al. The STARD9/Kif16a kinesin associates with mitotic microtubules and regulates spindle pole assembly. Cell 2011 147: $1309-1323$.

19. Hendzel MJ, Wei Y, Mancini MA, Van Hooser A, Ranalli T, Brinkley BR et al. Mitosis-specific phosphorylation of histone $\mathrm{H} 3$ initiates primarily within pericentromeric heterochromatin during G2 and spreads in an ordered fashion coincident with mitotic chromosome condensation. Chromosoma 1997; 106: 348-360.

20. Tanramluk D, Schreyer A, Pitt WR, Blundell TL. On the origins of enzyme inhibitor selectivity and promiscuity: a case study of protein kinase binding to staurosporine. Chem Biol Drug Des 2009; 74: 16-24.

21. Ruegg UTBurgess GM. Staurosporine, K-252 and UCN-01: potent but nonspecific inhibitors of protein kinases. Trends Pharmacol Sci 1989; 10: 218-220.

22. Osherov N, Gazit A, Gilon C, Levitzki A. Selective inhibition of the epidermal growth factor and HER2/neu receptors by tyrphostins. J Biol Chem 1993; 268 : 11134-11142.

23. Blenis J. Signal transduction via the MAP kinases: proceed at your own RSK. Proc Natl Acad Sci USA 1993; 90: 5889-5892.

24. Goekjian PG, Jirousek MR. Protein kinase $C$ inhibitors as novel anticancer drugs. Expert Opin Investig Drugs 2001; 10: 2117-2140.

25. Takeuchi N, Nakamura T, Takeuchi F, Hashimoto E, Yamamura H. Inhibitory effect of mitoxantrone on activity of protein kinase $\mathrm{C}$ and growth of HL60 cells. J Biochem 1992; 112 762-767.

26. Simon VR, Moran MF. SERCA activity is required for timely progression through G1/S. Cell Prolif 2001; 34: 15-30.

27. Aperia A. New roles for an old enzyme: Na,K-ATPase emerges as an interesting drug target. $J$ Int Med 2007; 261: 44-52.

28. Abbott BJ, Fukuda DS, Dorman DE, Occolowitz JL, Debono M, Farhner L. Microbial transformation of A23187, a divalent cation ionophore antibiotic. Antimicrob Agents Chemother 1979; 16: 808-812.

29. Tsimberidou AM, Alvarado Y, Giles FJ. Evolving role of ribonucleoside reductase inhibitors in hematologic malignancies. Expert Rev Anticancer Ther 2002; 2: 437-448.

30. Takahashi-Yanaga F, Sasaguri T. GSK-3beta regulates cyclin D1 expression: a new target for chemotherapy. Cellular Signal 2008; 20: 581-589.

31. Alao JP. The regulation of cyclin D1 degradation: roles in cancer development and the potential for therapeutic invention. Mol cancer 2007; 6: 24.

32. Kim HJ, Choo H, Cho YS, No KT, Pae AN. Novel GSK-3beta inhibitors from sequential virtua screening. Bioorg Med Chem 2008; 16: 636-643.

33. Nitiss JL. Targeting DNA topoisomerase II in cancer chemotherapy. Nat Rev Cancer 2009; 9 338-350.

34. Clifford B, Beljin M, Stark GR, Taylor WR. G2 arrest in response to topoisomerase inhibitors: the role of p53. Cancer Res 2003; 63: 4074-4081.
35. Morita T, Yoshino K, Kanazawa T, Ito K, Nose T. Vasodilator action of KB-944, a new calcium antagonist. Arzneimittelforschung 1982; 32: 1037-1042.

36. Miller RG, Mitchell JD, Lyon M, Moore DH. Riluzole for amyotrophic lateral sclerosis (ALS)/motor neuron disease (MND). Amyotroph Lateral Scler Other Motor Neuron Disord 2003; 4: 191-206

37. Song JH, Huang CS, Nagata K, Yeh JZ, Narahashi T. Differential action of riluzole on tetrodotoxin-sensitive and tetrodotoxin-resistant sodium channels. J Pharmacol Exp Ther 1997; 282: 707-714

38. Wagner ML, Landis BE. Riluzole: a new agent for amyotrophic lateral sclerosis. Ann Pharmacother 1997; 31: 738-744.

39. Sasaki J, Ramesh R, Chada S, Gomyo Y, Roth JA, Mukhopadhyay T. The anthelmintic drug mebendazole induces mitotic arrest and apoptosis by depolymerizing tubulin in non-small cell lung cancer cells. Mol Cancer Ther 2002; 1: 1201-1209.

40. Chavarria AP, Swartzwelder JC, Villarejos VM, Zeledon R. Mebendazole, an effective broadspectrum anthelmintic. Am J Trop Med Hyg 1973; 22: 592-595.

41. Sakaue-Sawano A, Kurokawa H, Morimura T, Hanyu A, Hama $\mathrm{H}$, Osawa $\mathrm{H}$ et al. Visualizing spatiotemporal dynamics of multicellular cell-cycle progression. Cell 2008; 132: 487-498.

42. Hutchins JR, Toyoda Y, Hegemann B, Poser I, Heriche JK, Sykora MM et al. Systematic analysis of human protein complexes identifies chromosome segregation proteins. Science 2010; 328: 593-599.

43. Bollag G, Tsai J, Zhang J, Zhang C, Ibrahim P, Nolop K et al. Vemurafenib: the first drug approved for BRAF-mutant cancer. Nat Rev Drug Discov 2012; 11: 873-886.

44. Salama AK, Kim KB. Trametinib (GSK1120212) in the treatment of melanoma. Expert Opin Pharmacother 2013; 14: 619-627.

45. Jordan MA, Wilson L. Microtubules as a target for anticancer drugs. Nat Rev Cancer 2004; 4: 253-265.

46. Sondergaard JN, Nazarian R, Wang Q, Guo D, Hsueh T, Mok S et al. Differential sensitivity of melanoma cell lines with BRAFV600E mutation to the specific Raf inhibitor PLX4032. J Transl Med 2010; 8: 39.

47. Zhang JH, Chung TD, Oldenburg KR. A simple statistical parameter for use in evaluation and validation of high throughput screening assays. J Biomol Screen 1999; 4: 67-73.

48. Torres JZ, Ban KH, Jackson PK. A specific form of phospho protein phosphatase 2 regulates anaphase-promoting complex/cyclosome association with spindle poles. Mol Biol Cell 2010; 21: $897-904$

(i) Cell Death and Disease is an open-access journal published by Nature Publishing Group. This work is licensed under a Creative Commons Attribution 4.0 International Licence. The images or other third party material in this article are included in the article's Creative Commons licence, unless indicated otherwise in the credit line; if the material is not included under the Creative Commons licence, users will need to obtain permission from the licence holder to reproduce the material. To view a copy of this licence, visit http://creativecommons.org/licenses/by/4.0 